\title{
CONCENTRAÇÃO REGIONAL DA PRODUÇÃO DE LENHA DA PARAÍBA
}

\author{
REGIONAL CONCENTRATION OF FIREWOOD PRODUCTION IN PARAÍBA
}

\author{
Luiz Moreira Coelho Junior ${ }^{1}$ Mariana de Castro Burgos ${ }^{2}$ Edvaldo Pereira Santos Júnior ${ }^{3}$
}

\begin{abstract}
RESUMO
Este artigo analisou a concentração regional da produção da lenha nativa da Paraíba, no período de 1994 a 2014. Os dados da quantidade produzida de lenha nativa foram extraídos da produção da extração vegetal e da silvicultura disponíveis no Instituto Brasileiro de Geografia e Estatística. A concentração regional foi determinada por meio dos indicadores: Razão de Concentração $[C R(k)]$, Índice de Herfindahl-Hirschman $(H H I)$, Entropia de Theil $(E)$, Índice Hall-Tindelman $(H T I)$ e o coeficiente de Gini $(G)$. A partir das análises realizadas neste estudo, conclui-se que no período estudado houve uma redução da produção de lenha na Paraíba, em virtude da atuação dos órgãos fiscalizadores e ambientais, passando de $1.173 .383 \mathrm{~m}^{3}$, em 1994, para $484.142 \mathrm{~m}^{3}$, em 2014; o $C R(k)$ da produção de lenha na Paraíba para as 4 maiores microrregiões apresentou-se concentração moderadamente baixa e para as 8 maiores microrregiões caracterizou-se como moderadamente alta; para os municípios indicou concentração baixa e mercado competitivo; o $H H I$ para os municípios e microrregiões demonstrou baixa concentração indicando um mercado altamente competitivo. Já às mesorregiões caracterizou concentração moderada para produção de lenha; o $E$ mostrou comportamentos semelhantes entre municípios e microrregiões demonstrando baixa concentração. A mesorregião teve pouca concorrência entre as regiões produtoras de lenha inferindo concentração moderada, corroborando assim o HHI; o HTI também apresentou baixa concentração nos níveis regionais (municípios, microrregiões e mesorregiões), indicando concorrência elevada como os demais indicadores; o $G$ mostrou desigualdade de nula a fraca para os municípios, obteve desigualdade fraca a média nas microrregiões, e desigualdade média a forte nas mesorregiões.
\end{abstract}

Palavras-chave: economia florestal; biomassa; competitividade.

\begin{abstract}
This paper analyzed the regional concentration of firewood production in Paraíba state, from 1994 to 2014. The data on the quantity of native firewood produced were extracted from the production of the vegetal extraction and forestry available at the Brazilian Institute of Geography and Statistics (Instituto Brasileiro de Geografia e Estatística). The regional concentration was determined through the indicators: Concentration Ratio $[C R(k)]$, Herfindahl-Hirschman Index $(H H I)$, of Theil's Entropy index $(E)$, the Hall-Tindelman Index $(H T I)$ and the Gini Index $(G)$. From the analyzes carried out in this study, it was concluded that during the period studied there was a reduction in the production of firewood in Paraíba state, due to the performance of the inspection and environmental agencies, from $1,173,383 \mathrm{~m}^{3}$ in 1994 to $484,142 \mathrm{~m}^{3}$ in 2014 ; The $C R(k)$ of the firewood production in Paraíba for the 4 largest microregions presented a moderately low concentration and for the 8 largest microregions it was characterized as moderately high; for municipalities demonstrated low concentration and competitive market; the $H H I$ for the municipalities and microregions showed low concentration indicating a highly competitive market. In the mesoregions, there was a moderate concentration of firewood production; and $E$ showed similar behaviors between municipalities and microregions showing low concentration. The mesoregion had little competition among the firewood

1 Economista, Dr., Professor do Departamento de Engenharia de Energias Renováveis, Universidade Federal da Paraíba, Caixa Postal 5115, CEP 58051-900, João Pessoa (PB), Brasil. luiz@cear.ufpb.br

2 Administradora, Funcionária da Universidade Federal da Paraíba, CEP 58051-900, João Pessoa (PB), Brasil. marianaburgos20@gmail.com

3 Graduando em Engenharia, Universidade Federal da Paraíba, CEP 58051-900, João Pessoa (PB), Brasil. edvaldo.junior@cear.ufpb.br
\end{abstract}

Recebido para publicação em 6/09/2017 e aceito em 1/11/2017

Ci. Fl., v. 28, n. 4, out. - dez., 2018 
regions, inferring moderate concentration, thus corroborating HHI; HTI also presented low concentration at regional levels (municipalities, microregions and mesoregions), indicating high competition as the other indicators; the $G$ showed inequality from zero to weak for the municipalities, it obtained weak inequality in the microregions, and medium to strong inequality in the mesoregions.

Keywords: forest economy; biomass; competitiveness.

\section{INTRODUÇÃO}

O potencial energético da biomassa é enorme, tanto em escala mundial como no Brasil. A biomassa florestal possui características que permitem a utilização limpa e renovável dos recursos, seja nos processos de transformação da madeira em lenha, carvão vegetal, resíduos de cultivo, resíduos de processamento industrial, plantações energéticas e para geração de eletricidade (MACEDO, 2003). Quando há florestas plantadas com fins energéticos, agrega-se a geração de emprego e renda (SOARES et al., 2006).

A biomassa florestal ocupa papel importante na matriz energética brasileira, tendo como principal uso o carvão vegetal e a lenha. De acordo com o Balanço Energético Nacional (BEN), no ano de 2013, a madeira foi responsável por 9,5\% da produção de energia primária (MIRANDA, 2015). Segundo a Indústria Brasileira de Árvores - IBA (2014), o consumo brasileiro de madeira de árvores plantadas para uso industrial foi de 185,3 milhões de metros cúbicos $\left(\mathrm{m}^{3}\right)$, o que representou aumento de $1,8 \%$ em relação ao consumo de 2012.

No Brasil, em 2014, o valor do extrativismo vegetal e silvicultura chegaram a $\mathrm{R} \$ 20,8$ bilhões. A produção da silvicultura contribuiu com $77,7 \%$ ( $\$$ \$ 16,1 bilhões), enquanto a extrativismo vegetal participou com $22,3 \%$ (R $\$ 4,6$ bilhões). Na silvicultura, o valor de produção dos produtos madeireiros chegou a R \$ 15,9 bilhões e o dos não madeireiros, a R \$ 216 milhões. Já no extrativismo vegetal, o valor de produção dos produtos madeireiros totalizou $\mathrm{R} \$ 3,2$ bilhões e a de não madeireiros somou R \$ 1,4 bilhão (INSTITUTO BRASILEIRO DE GEOGRAFIA E ESTATÍSTICA - IBGE, 2016).

O nordeste possui alta dependência dos recursos florestais nativos, da lenha e do carvão vegetal na matriz energética, seja nos domicílios e na indústria. Em 2011, o nordeste produziu aproximadamente 30 milhões de estéreos (st) de lenha. Foram 22,7 milhões st de lenha e 616.541 toneladas (t) de carvão vegetal oriundo de florestas nativas, o que equivale a 7,25 milhões st de lenha utilizados na produção do carvão vegetal, considerando uma relação de $85 \mathrm{~kg} / \mathrm{st}$ (IBGE, 2016; SOARES et al., 2006).

No semiárido do nordeste brasileiro, a vegetação predominante é a Caatinga. Sua exploração desequilibrada resulta na redução dos recursos florestais e da cobertura dos solos o que favorece na degradação desse bioma. A consequência da extração desenfreada é o desencadeamento do processo de desertificação e elevação da vulnerabilidade socioambiental regional (CARVALHO, 2012).

$\mathrm{Na}$ Paraíba, em 2015, a quantidade de lenha produzida no extrativismo vegetal foi de 735 toneladas de carvão vegetal e 495.625 metros cúbicos de lenha. Para os produtos da silvicultura, a quantidade produzida da lenha foi de 54.700 metros cúbicos e de madeira em tora foi de 144.560 metros cúbicos (IBGE, 2016). A indústria de cerâmica é grande consumidora de lenha, que utiliza na queima e secagem de seus produtos. A lenha é mais barata quando comparada aos combustíveis disponíveis e se tornou uma a principal fonte da matriz energética desta indústria na região (CENTRO DE TECNOLOGIA DO GÁS E ENERGIAS RENOVÁVEIS - CTGAS, 2012). Na Paraíba, os dois polos produtores de cerâmica estão presentes na região de João Pessoa e Santa Luzia, e juntos consomem aproximadamente 900.000 st.ano $^{-1}$ de lenha (REINALDO FILHO; BEZERRA, 2010).

A concentração industrial se relaciona com o poder de mercado que envolve as empresas e suas atividades econômicas, sendo um dos componentes a concorrência. A concentração e a concorrência apresentam uma relação inversa, uma vez que, na medida em que a concentração aumenta, diminui o grau de competição, aumentando o poder de mercado (POSSAS, 1999). Para analisar a estrutura de mercado, se faz necessário o uso de indicadores para se evidenciar o grau de concentração e verificar a estrutura competitiva da indústria na região.

Para ensaios de concentração no setor florestal, Coelho Junior, Rezende e Oliveira (2013) analisaram a concentração das exportações mundiais de produtos florestais. Coelho Junior (2016) para o valor bruto de produção do pinhão no Paraná e Schettini et al. (2016) para o mercado mundial de pellets de madeira. 
Simioni et al. (2017) realizaram estudos da evolução e concentração da produção de lenha e carvão vegetal da silvicultura no Brasil. Coelho Junior et al. (2018) ponderaram a concentração das exportações mundiais de celulose. Lima Júnior (2013) estudou o aproveitamento energético de fontes de biomassa no Nordeste. Em estudos a respeito da lenha no Nordeste destacam-se em Souza e Travassos (2014) e Chaves (2016).

A hipótese deste trabalho foi que a produção da lenha na Paraíba não está concentrada regionalmente. As medidas de concentração auxiliam na tomada de decisão fornecendo elementos empíricos necessários, principalmente, na orientação de políticas públicas que visem ao crescimento e a competitividade do setor. Em busca de uma melhor compreensão da oferta de lenha na Paraíba. Este trabalho analisou a concentração regional da produção da lenha na Paraíba, no período de 1994 a 2014.

\section{MATERIAL E MÉTODOS}

\section{Objeto de estudo}

A Figura 1 mostra a localização geográfica do estado da Paraíba no Brasil e na região Nordeste. Os dados necessários para medir a concentração regional da produção da Lenha nativa na Paraíba, no período de 1994 a 2014, foram extraídos da Produção da Extração Vegetal e da Silvicultura (PEVS) por meio do Sistema de Recuperação Automática (SIDRA), do Instituto Brasileiro de Geografia e Estatística (IBGE) (IBGE, 2017a). A concentração regional estudada foi para os níveis municipais, microrregiões e mesorregiões.

Os índices utilizados para mensuração da concentração regional foram: Razão de Concentração $[C R(k)]$, o Índice de Herfindahl-Hirschman (HHI), a Entropia de Theil $(E)$ o Índice Hall-Tindelman (HTI) e o Índice de Gini $(G)$, descritos a seguir.

\section{Razão de Concentração}

A Razão de Concentração $[C R(k)]$ analisa a participação no mercado das $k$ (sendo $k=1,2, \ldots, n$ ) regiões produtoras de lenha da Paraíba (BAIN, 1959). A equação é $C R(k)=\sum_{i=1}^{k} s_{i}$, em que, $S_{i}$ é o market share, em porcentagem, da região $i$ (municípios e microrregiões) para a produçã̃o de lenha.

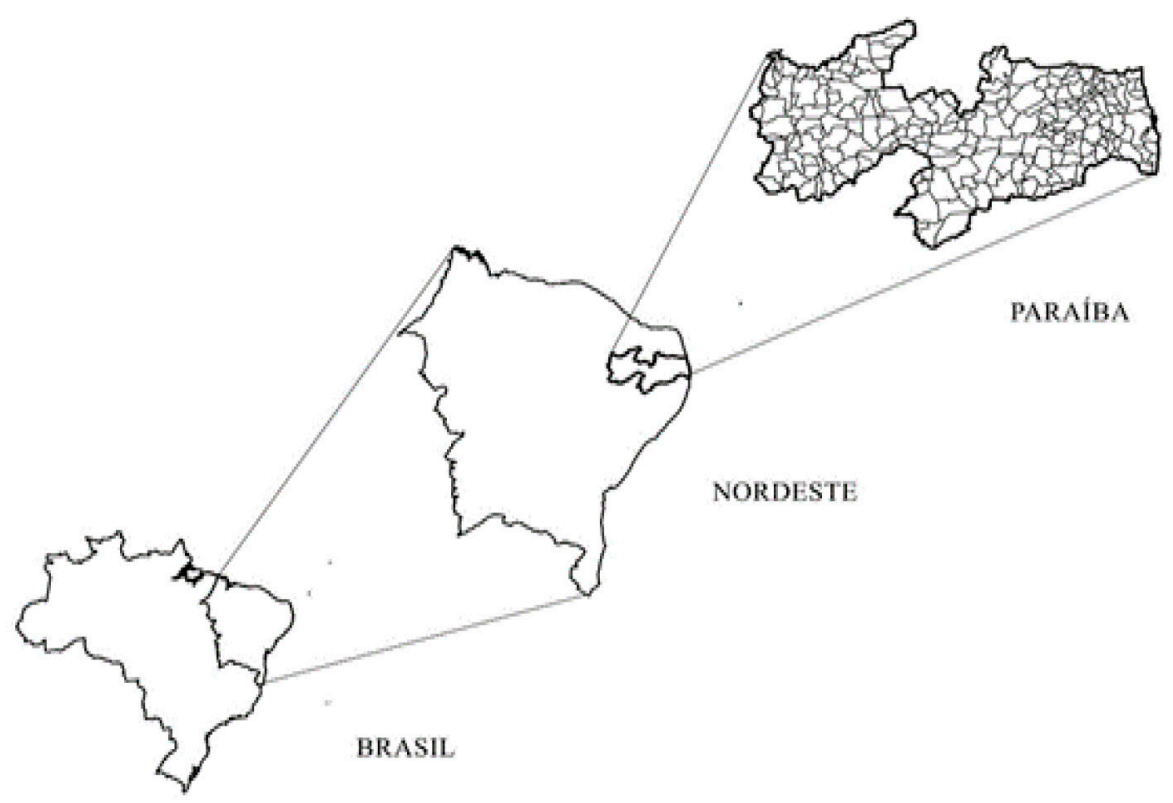

FIGURA 1: Localização da área de estudo (Fonte: IBGE, 2017b).

FIGURE 1: Location of the study area. 
Para o cálculo da razão de concentração, as participações das regiões foram ordenadas de forma decrescente. De acordo a classificação Bain (1959), a Tabela 1 ilustra os diferentes níveis de concentração e as respectivas classificações às participações dos 4 maiores [CR(4)] e 8 maiores [CR(8)]. Normalmente, o $C R(4)$ e $C R(8)$ são os mais utilizados nas análises de concentração. Foram mensurados estes indicadores para os municípios e microrregiões produtoras de lenha na Paraíba e, também, verificando os 20 maiores $[C R(20)]$ e 30 maiores $[C R(30)]$ municípios produtores de lenha na Paraíba.

TABELA 1: Classificação do Razão de Concentração [CR(k)].

TABLE 1: Classification of the concentration ratio [CR $(k)]$.

\begin{tabular}{lcc}
\hline \multicolumn{1}{c}{ Grau de Concentração } & CR (4) & CR $(8)$ \\
\hline Muito Alto & $75 \%$ ou mais & $90 \%$ ou mais \\
Alto & $65 \%-75 \%$ & $85 \%-90 \%$ \\
Moderadamente Alto & $50 \%-65 \%$ & $70 \%-85 \%$ \\
Moderadamente Baixo & $35 \%-50 \%$ & $45 \%-70 \%$ \\
Baixo & $35 \%$ ou menos & $45 \%$ ou menos \\
\hline
\end{tabular}

Fonte: Bain (1959).

\section{Índice de Herfindahl-Hirschman}

O Índice Herfindahl-Hirschman (HHI) é uma ferramenta de análise de concentração de mercado proposta por Hirschman (1945) e Herfindahl (1950). Em 1964, Hirschman publicou a obra "The Paternity of an Index" que reivindica a posse original do índice (HIRSCHMAN, 1964). O HHI demonstra a participação de cada região no valor bruto de produção da lenha na Paraíba.

O HHI mensura a concentração industrial utilizando os dados de todas as regiões, em dado setor produtivo, por meio de $H H I=\sum^{n} S_{i}^{2}$, em que, $S_{i}$ é o market share, em porcentagem, da região (municípios, microrregião e mesorregião) $i$ para a quantidade produzida de lenha na Paraíba. $n$ é o número de participantes da quantidade produzida de lenha na Paraíba, nos seus níveis regionais.

O valor do índice oscila entre $1 / n$ (limite inferior) com participações iguais de cada região e 1 (concentração máxima), quando há uma situação de monopólio. Para análises comparativas intertemporais, Resende (1994) sugeriu o Índice Herfindahl-Hirschman ajustado como $H H I^{\prime}=\frac{1}{n-1}(n H H I-1)$, sendo $n>1$. O HHI' implica em um intervalo de variação entre 0 e 1 . Assim, à medida que o índice se afasta de zero, a concentração será maior. Ou seja, um índice $H H I^{\prime}<0,10$ indica um mercado altamente competitivo. Um índice no intervalo $0,10 \leq H H I^{\prime}<0,15$ indica um mercado não concentrado. Um índice no intervalo 0,15 $\leq H H I^{\prime} \leq 0,25$ indica concentração moderada. E, um índice $H H I^{\prime}>0,25$ indica alta concentração.

\section{Índice de Entropia de Theil}

Proposto Theil (1967), o Índice de Entropia foi inicialmente formulado para se verificar o conteúdo informacional da mensagem que as firmas transmitiriam, dado o grau de surpresa que as mesmas teriam, diante de certo evento. O índice, porém, pode ser aplicado avaliando a concentração regional da lenha na Paraíba. A equação utilizada para o cálculo da Entropia é $E=-\sum_{i=1}^{n} \ln \left(S_{i}\right)$, em que, $S_{i}$ é o market share, em porcentagem, da região (municípios, microrregião e mesorregião) $i$ para a quantidade produzida de lenha na Paraíba; $n$ é o número de participantes da quantidade produzida de lenha na Paraíba, nos seus níveis regionais; ln é o logaritmo neperiano.

$\mathrm{O}$ índice de Entropia mede o inverso da concentração do $H H I$, em que o índice oscila entre 0 
(concentração máxima) e $\ln (n)$ (concentração mínima). Quanto menor o valor do índice mais concentrada regionalmente é o valor da quantidade produzida de lenha na Paraíba. Em situações de monopólio, o valor da Entropia é igual a zero. Já o limite superior é igual a $\ln (n)$, isto é, as regiões possuem parcelas iguais de mercado e concentração mínima (BOFF; RESENDE, 2002). De forma análoga ao sugerido para o $H H I$, Resende (1994) sugeriu, para análises intertemporais, a Entropia ajustada como $E^{\prime}=\frac{1}{n-1} \sum_{i=1}^{n} s_{i} \ln \left(s_{i}\right)$. Assim, a entropia passa a variar entre 0 , monopólio (concentração máxima), e 1, concorrência perfeita (concentração mínima).

\section{Índice de Hall-Tindelman}

Para Bikker e Haaf (2001), o índice de Hall-Tindelman (HTI) alia os $n$ elementos no indicador. Neste índice, a participação de cada região recebe um peso igual ao seu ranking na construção do indicador e assim a ênfase passa a ser o número total de regiões produtoras de lenha na Paraíba. Sua representação matemática é $H T I=\frac{1}{2 \sum_{i=1}^{n}\left(i s_{i}\right)-1}$, em que, $S_{i}$ é o market share, em porcentagem, da região (municípios, microrregião e mesorregião) $i$ para a quantidade de lenha; $n$ é o número de regiões participantes na quantidade produzida de lenha; $i$ é a posição ocupada pela região em ordem decrescente da quantidade produzida de lenha da Paraíba. Logo, cada região possui peso igual ao seu ranking no conjunto das regiões. O valor do $H T I$ varia entre $1 / \mathrm{n}$ e 1 , sendo aproximado do primeiro para um certo número de elementos do mesmo tamanho e atingindo 1 (um) caso de monopólio (alta concentração).

\section{Índice de Gini}

O Coeficiente de Gini (G) é uma medida de desigualdade desenvolvida por Gini (1912) na obra "Variabilità e mutabilità". Este coeficiente, originalmente formulado para medir a desigualdade de renda pode, também, ser usado para medir o grau de desigualdade da quantidade produzida de lenha em uma região. O índice é uma ferramenta acessória aos coeficientes de concentração, uma vez que uma concentração elevada implica em uma desigualdade maior. O cálculo do índice é $G=1-\left[\frac{\sum_{i=1}^{n}\left(s_{i j}+s_{i}\right)}{n}\right\rceil$, em que, $n$ é o número de regiões produtoras de lenha na Paraíba; $S_{i j}$ é a participação cumulativa da quantidade produzida de lenha em ordem crescente; $S_{i}$ é o market share, em porcentagem, da quantidade produzida de lenha $i$ do total consumido da indústria. O índice varia entre 0 e 1, classificado da seguinte forma: $0,101-0,250$ desigualdade nula a fraca; 0,251 - 0,500 desigualdade fraca a média; 0,501 - 0,700 desigualdade média a forte; $0,701-0,900$ desigualdade forte a muito forte; $0,900-1,000$ desigualdade muito forte a absoluta.

\section{RESULTADOS E DISCUSSÃO}

A Tabela 2 apresenta a evolução da produção de lenha nativa das mesorregiões do estado da Paraíba, no período de 1994 a 2014. Houve uma diminuição da quantidade produzida, passando de $1.173 .383 \mathrm{~m}^{3}$, em 1994, para $484.142 \mathrm{~m}^{3}$, em 2014. De acordo com a Agência Brasil (2017), essa redução ao longo dos anos se deu devido à crise econômica brasileira que afetou todos os produtos madeireiros do extrativismo vegetal, com decréscimo generalizado na quantidade obtida, tendo à frente o carvão vegetal, cuja retração foi de $21,9 \%$, seguido da lenha $(-6,8 \%)$ e que refletiu no cenário paraibano. O IBGE (2016) informou que tais quedas também estão diretamente relacionadas à atuação de órgãos fiscalizadores e ambientais. De 1994 a 2014, o Sertão Paraibano se manteve como maior produtor de lenha no período, seguido da Borborema e do Agreste Paraibano. Essas três mesorregiões apresentaram tendências de declínio na produção de 
lenha. A Mata Paraibana se manteve em quarto lugar, com uma contribuição muito pequena no contexto estadual, devido aos fragmentos florestais serem voltados, praticamente, para área de preservação permanente, reserva legal e unidades de conservação.

TABELA 2: Evolução da produção de lenha nativa nas Mesorregiões na Paraíba, em metros cúbicos, no período de 1994 a 2014.

TABLE 2: $\quad$ Evolution of the firewood production in Mesoregions of Paraíba, in cubic meters, from 1994 to 2014.

\begin{tabular}{lcccccc}
\hline \multicolumn{1}{c}{ Mesorregiões } & 1994 & 1998 & 2002 & 2006 & 2010 & 2014 \\
\hline Sertão Paraibano & 614.314 & 466.203 & 421.992 & 364.049 & 315.248 & 247.187 \\
Borborema & 289.824 & 281.818 & 220.481 & 176.809 & 197.865 & 170.555 \\
Agreste Paraibano & 257.355 & 131.929 & 96.813 & 83.978 & 73.029 & 64.495 \\
Mata Paraibana & 11.890 & 17.880 & 350 & 405 & 2.940 & 1.905 \\
\hline Paraíba & 1.173 .383 & 897.830 & 739.636 & 625.241 & 589.082 & 484.142 \\
\hline
\end{tabular}

Fonte: IBGE (2016).

A Figura 2 mostra a razão de concentração da quantidade produzida de lenha no Estado da Paraíba, por meio de suas microrregiões e municípios, no período de 1994 a 2014. Para a Figura 2.a., a razão de concentração das 4 maiores microrregiões $\left[C R(4)_{\text {Micro }}\right]$ e apresentou média de $47 \%$ no período observado, considerado uma concentração moderadamente baixa, conforme as orientações de classificação de Bain (1959). Quando as quatro microrregiões produtoras de lenha detêm mais de $40 \%$ do mercado, a estrutura desse mercado é oligopolista (SCHERER; ROSS, 1990). A maior concentração para o $C R(4)_{\text {Micro }}$ foi, em 1995, 56,76\% e a menor, em 1996, 37,89\%. A partir de 1997 o $C R(4)_{\text {Micro }}$ teve percentuais maiores, porém, permanecendo com uma concentração moderadamente baixa. As microrregiões que colaboraram com o $C R(4)_{\text {Micro }}$ em pelo menos uma vez no período estudado foram: Itaporanga, Cariri Ocidental, Catolé do Rocha e Sousa, Piancó, Serra do Teixeira, Cariri Oriental, Curimataú Ocidental, Seridó Ocidental e Cajazeiras.

A razão de concentração das 8 maiores microrregiões $\left[C R(8)_{\text {Micro }}\right.$ ] apresentou uma média de $74 \%$, mostrando uma concentração alta. A maior concentração foi, em 1995, 81,59\% e a menor, em 1996, 64,22\% como concentração moderadamente alta. A microrregião que participou do $C R(8)_{\text {Micro }}$ em todo o período estudado foi Catolé do Rocha. Outras microrregiões que colaboraram na composição do $C R(8)_{\text {Micro }}$ em pelo menos uma vez foram: Itaporanga, Cariri Ocidental, Sousa, Cariri Oriental, Serra do Teixeira, Piancó, Seridó Ocidental Paraibano, Curimataú Ocidental, Seridó Oriental Paraibano, Cajazeiras e Patos.
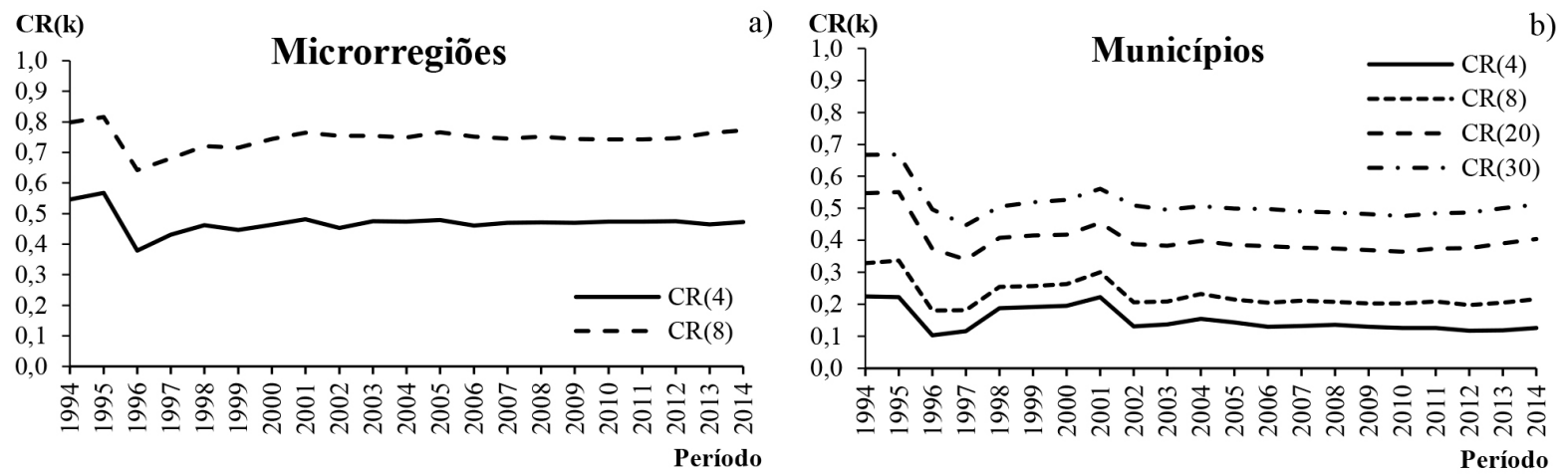

FIGURA 2: Evolução da razão de concentração $[C R(k)]$ da quantidade produzida de lenha na Paraíba, em nível municipal e microrregional, no período de 1994 a 2014.

FIGURE 2: Evolution of the concentration ratio $[C R(k)]$ of firewood production in Paraíba state, at municipal and microregional levels, from 1994 to 2014. 
A Figura 2.b. mostra que a razão de concentração dos 4 maiores municípios $\left[C R(4)_{\text {Munic }}\right]$ ficou classificada como de concentração baixa, pois obteve $15 \%$ em média no período estudado, conforme Bain (1959). O maior $C R(4)_{\text {Munic }}$ foi, em 1994, 22,24\% e o menor esteve com 10,30\%, em 1996. Os municípios que colaboraram na composição do $C R(4)_{\text {Munic }}$ foram: Conceição, Itaporanga, Taperoá, Sousa, Boqueirão e Piancó. Os municípios que colaboraram pelo menos uma vez foram: Pombal, Soledade, Umbuzeiro, Manaíra, Coremas, Barra de São Miguel, Barra de Santa Rosa, Mari, Nova Olinda, Mato Grosso, Damião e Diamante.

A razão de concentração dos 8 maiores municípios $\left[C R(8)_{\text {Munic }}\right]$ apresentou uma média de $22 \%$ no período estudado, caracterizando-o com concentração baixa. O ano de maior concentração foi em 1995 , com 33,66\% e a menor foi em 1996, com 18,05\%. Os Municípios que contribuíram na composição do $C R(8)_{\text {Munic }}$ foram: Conceição, Itaporanga, Taperoá, Boqueirão, Sousa, Piancó, Junco do Seridó, Catolé do Rocha, Diamante e Barra de São Miguel. Outros municípios que contribuíram pelo menos uma vez foram: Juazeirinho, Barra de Santa Rosa, Umbuzeiro, Pombal, Coremas, Manaíra, Congo e Emas.

A razão de concentração dos 20 maiores municípios [CR(20) ${ }_{\text {Munic. }}$ ] obteve média de $40 \%$ e a razão de concentração dos 30 maiores municípios [CR(30) ${ }_{\text {Munic. }}$ apresentou uma média de $51 \%$ (Figura 1.b). Estes dois $C R(k ' s)$ indicam que um mercado não concentrado, visto que cerca de $50 \%$ do mercado atuou os 30 maiores municípios produtores de lenha.

A Figura 3 representa a evolução do Índice de Herfindahl-Hirschman $(H H I)$ da quantidade produzida de lenha na Paraíba, por meio de municípios, microrregiões e mesorregiões, no período de 1994 a 2014. O $H H I$ municipal $\left(H H I_{\text {Munic }}\right)$ e o $H H I$ microrregional $\left(H H I_{\text {Micro }}\right)$ tiveram comportamentos semelhantes, apresentando um mercado altamente competitivo. Já o $H H I$ mesorregional $\left(H H I_{\text {Meso }}\right)$ demonstrou um mercado moderadamente concentrado. Para o $H H I$ dos municípios $\left(H H I_{\text {Munic }}\right)$ obteve média de 0,015 no período analisado, enquanto a do $L I$ foi de 0,0053 (Figura 3.a). Observando a diferença entre o $H H I$ e $L I$ o ano de maior concentração foi 1994, com diferença de 0,018 .

Durante todo o período analisado, o índice se manteve bem próximo do limite inferior, demostrando baixa concentração na quantidade produzida de lenha na Paraíba. Para o HHI das microrregiões (HHIMicro ) apresentou média de 0,088 enquanto a do $L I$ foi de 0,046, no período de 1994 a 2014 (Figura 3.b). Observando a diferença entre o $H H I_{\text {Micro }}$ e $L I$, o ano de maior concentração foi 1995, com diferença de 0,065 . Já em 1996, foi a menor concentração dada pela diferença de 0,024 entre o $H H I$ e o $L I$, observando-se uma pequena queda do $H H I_{\text {Micro }}$ no início de período de análise, pois a participação das microrregiões variou de 22 para 23. A partir de 2000 , esta participação variou entre 21 e 22 microrregiões e o $H H I_{\text {Micro }}$ demonstrou mercado não concentrado, mantendo-se próximo do limite inferior.

$\mathrm{O} H H I$ das mesorregiões $\left(H H I_{\text {Meso }}\right)$ apresentou maior distância entre o seu limite inferior. Apesar da quantidade de regiões participantes ter sido a mesma, o $H_{H} I_{\text {Meso }}$ foi o que mais variou ao longo do período em análise, caracterizando a oferta de lenha na paraíba como concentração moderada (Figura 3.c). A média do $H H I_{\text {Meso }}$ no período estudado foi de 0,4106 enquanto do $L I$ foi de 0,25 . O ano de maior concentração 2014, com diferença entre o $H H I$ e $L I$ de 0,193 .

Para o HHI' ajustado (Figura 3.d) da produção de lenha na Paraíba, no período de 1994 a 2014, o $H I^{\prime}{ }_{\text {meso }}$ foi o que se mais destacou dada a elevada produção nas mesorregiões do Sertão Paraibano e Borborema quando comparada as demais regiões, indicando uma concentração moderada. $\mathrm{O} H H I^{\prime}{ }_{\text {Munic }} \mathrm{e}$ $H I^{\prime}{ }_{\text {Micro }}$ se mantiveram bem próximos ao longo do período analisado, apresentando um mercado altamente competitivo.

A Figura 4 apresenta a evolução do Índice de Entropia de Theil $(E)$ da produção de lenha na Paraíba, no período de 1994 a 2014. Os indicadores de entropia nos níveis regionais da Paraíba (municípios, microrregiões e mesorregiões) se mantiveram próximos do limite superior $(L S)$ e indicaram pouca variação, porém, em escalas de entropia distintas no período analisado (Figuras 4.a, 4.b e 4.c).

A produção de lenha para os municípios paraibanos apresentaram $E$ médio de $4,45 \%$ ficando com a menor concentração de mercado e maior distância entre o índice $\left(E_{\text {Munic }}\right)$ e o seu limite inferior. A microrregião demonstrou pouca variação do índice de entropia $\left(E_{\text {Micro }}\right)$ ficando mais próximo de seu limite inferior, com média de 2,63 e uma concentração moderada. A mesorregião obteve média de 0,99 , sendo considerada a região mais concentrada da Paraíba. A distância entre o índice $\left(E_{\text {Meso }}\right)$ e o seu limite foi bem pequena e os 
indicadores se mantiveram bem estáveis, demostrando pouca concorrência da quantidade de lenha produzida. De acordo com o índice de entropia ajustado (Figura 4.d), as regiões paraibanas indicaram uma estrutura de mercado competitivo, que resulta em uma concentração mínima das regiões ao longo dos anos em estudos.

A Figura 5 apresenta a evolução do Índice de Hall-Tindelman e do coeficiente de Gini da produção de lenha na Paraíba, em níveis regionais, no período de 1994 a 2014. Os índices $H T I$ e $G$ demonstraram pequenas variações em relação à média ao longo do período analisado, conforme indicam as Figuras $5 \mathrm{a} e$ 5b. De acordo com o gráfico HTI (Figura 5.a), as regiões da paraíba demonstraram uma baixa concentração. Os municípios e microrregiões apresentaram pouca variação e estiveram bem próximos da concentração mínima durante o período analisado, demostrando uma concorrência elevada.
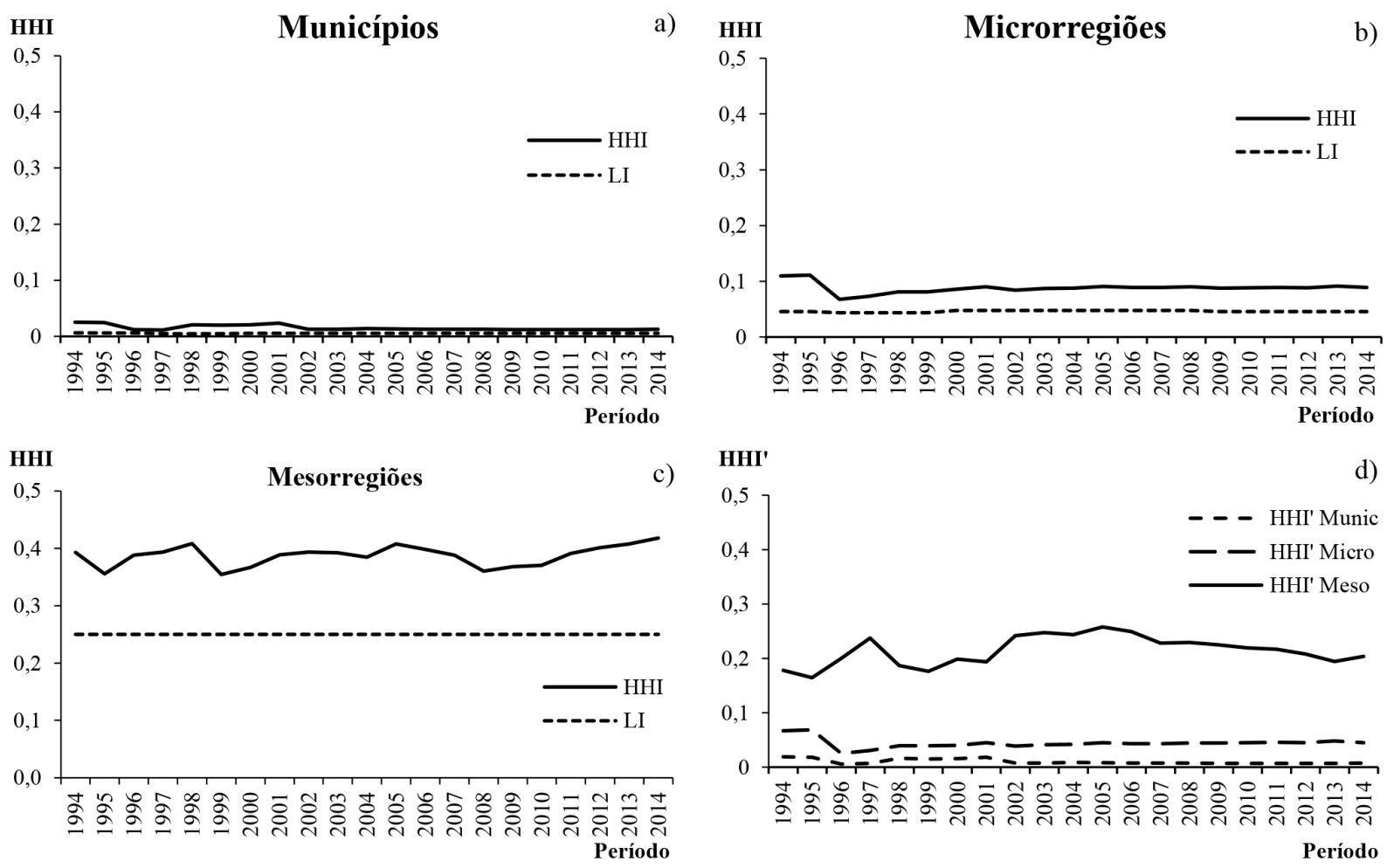

FIGURA 3: Evolução do Índice Herfindahl-Hirschman para a produção de lenha na Paraíba, nos níveis regionais, no período de 1994 a 2014.

FIGURE 3: Evolution of the Herfindahl-Hirschman Index of firewood production in Paraíba state, at regional levels, from 1994 to 2014. 

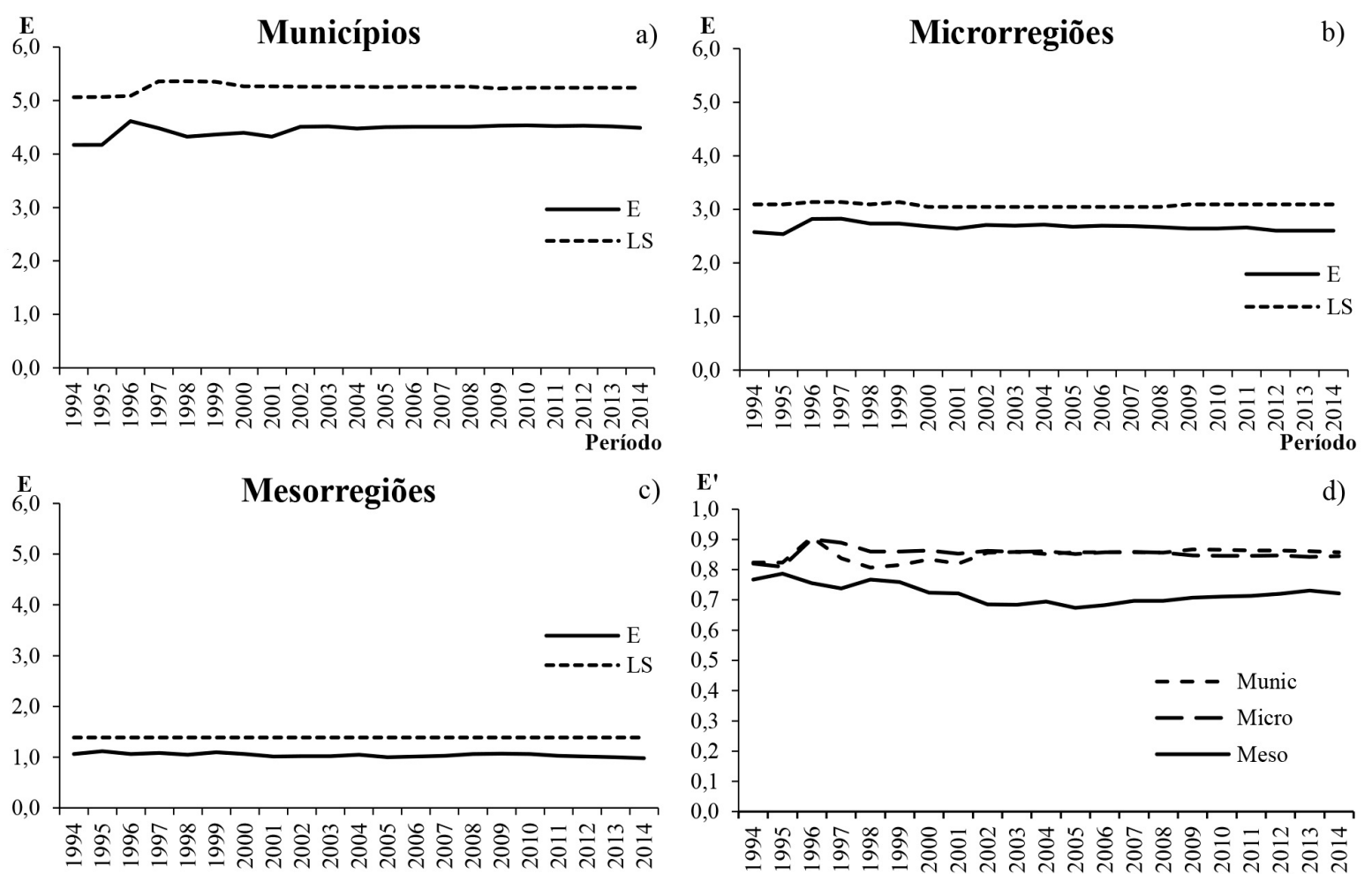

c) $\mathbf{E}^{\prime}$

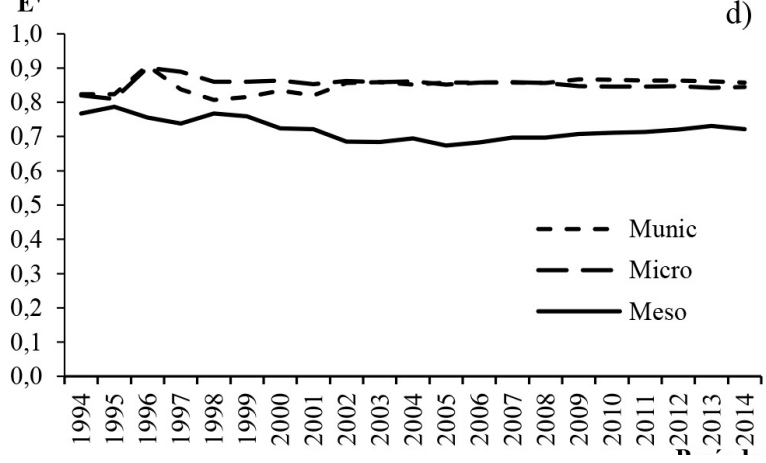

FIGURA 4: Evolução do Índice de Entropia da produção de lenha da Paraíba, em níveis regionais, no período de 1994 a 2014.

FIGURE 4: Evolution of Theil's Entropy Index of firewood production in Paraíba state, at regional levels, from 1994 to 2014.

Para os municípios, o $H T I_{M u n i}$ obteve média de participação de 0,0125 e a menor concentração a nível regional no período analisado, já o $H T I_{\text {Micro }}$ obteve média de 0,0683 indicando que nessas duas regiões apresenta-se um mercado não concentrado de empresas. O $H T I_{\text {Meso }}$ foi o indicador que mais apresentou tendências de declínio e crescimento, ficando com uma média de 0,3938 , indicando a maior concentração a nível regional.

O $G$ mostra a desigualdade da quantidade produzida de lenha na Paraíba (Figura 5.b). Foi demonstrado que houve pouca variação do índice em relação a média entre os níveis regionais, sem fortes tendências de declínio ou crescimento. No período estudado, o índice $G_{\text {Munic }}$ apresentou média de 0,2224 classificando-a desigualdade de nula a fraca; o índice $G_{\text {Micro }}$ teve média de 0,3159 qualificando como desigualdade fraca a média e; o índice $\mathrm{G}_{\text {Meso }}$ foi classificado com desigualdade média a forte, com média de 0,6552 . 

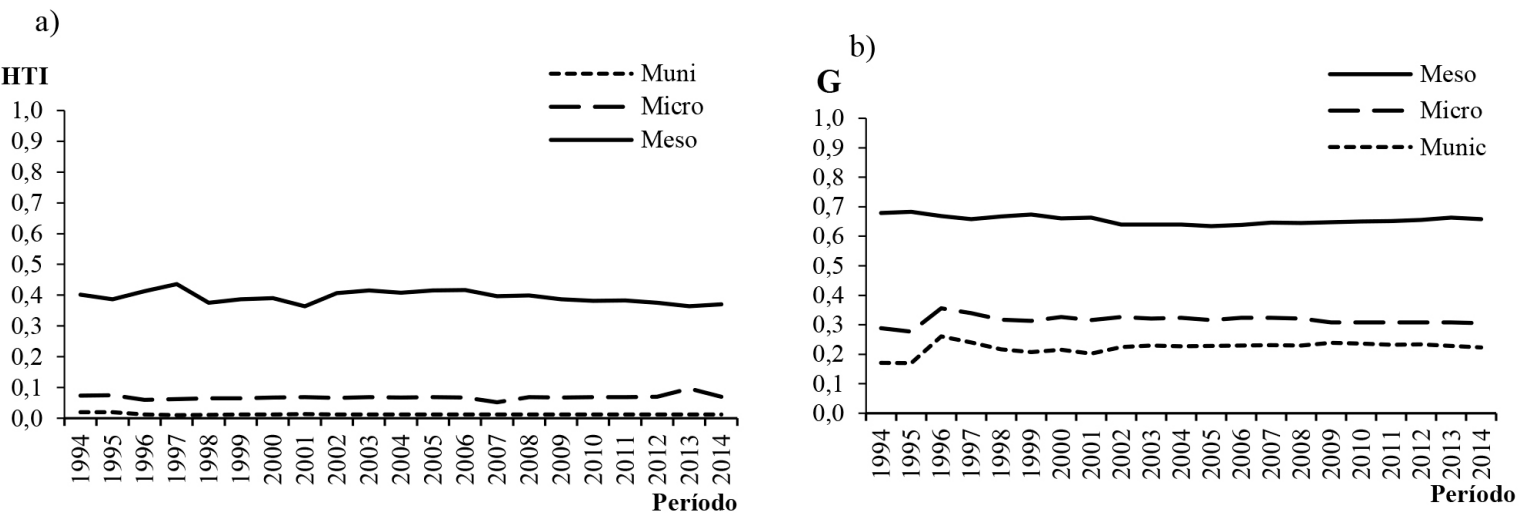

FIGURA 5: Evolução do índice de Hall-Tindelman e do coeficiente de Gini da produção de lenha da Paraíba, em níveis regionais, no período de 1994 a 2014.

FIGURE 5: Evolution of the Hall-Tindelman index and the Gini coefficient of the firewood production in Paraíba state, at regional levels, from 1994 to 2014.

\section{CONCLUSÕES}

A partir das análises realizadas neste estudo, conclui-se que:

No período estudado houve uma redução da produção de lenha na Paraíba, em virtude da atuação dos órgãos fiscalizadores e ambientais, passando de $1.173 .383 \mathrm{~m}^{3}$, em 1994, para $484.142 \mathrm{~m}^{3}$, em 2014;

$\mathrm{O} C R(k)$ da produção de lenha na Paraíba para as 4 maiores microrregiões apresentou-se concentração moderadamente baixa e para as 8 maiores microrregiões $\left[C R(8)_{\text {Micro }}\right]$ caracterizou-se como moderadamente alta; para os municípios indicou concentração baixa e mercado competitivo;

O Índice de Herfindahl-Hirschman para os municípios e microrregiões demonstrou baixa concentração indicando um mercado altamente competitivo. Já às mesorregiões caracterizou concentração moderada para produção de lenha;

O Índice de Entropia de Theil mostrou comportamentos semelhantes entre municípios e microrregiões demonstrando baixa concentração. A mesorregião teve pouca concorrência entre as regiões produtoras de lenha inferindo concentração moderada, corroborando assim o $H H I$;

O Índice de Hall-Tindelman também apresentou baixa concentração nos níveis regionais (municípios, microrregiões e mesorregiões), indicando concorrência elevada como os demais indicadores;

O coeficiente de Gini mostrou desigualdade de nula a fraca para os municípios, obteve desigualdade fraca a média nas microrregiões, e desigualdade média a forte nas mesorregiões.

\section{AGRADECIMENTOS}

Os autores agradecem ao Conselho Nacional de Desenvolvimento Científico e Tecnológico (CNPq) pelas bolsas concedidas pelo Programa Institucional de Bolsas de Iniciação Científica (PIBIC) e pelo apoio financeiro do projeto $n^{\circ} 454830$ / 2014-9.

\section{REFERÊNCIAS}

Agência Brasil - EBC. Produção de carvão vegetal-lenha e madeira em tora do extrativismo. Disponível em: <http://agenciabrasil.ebc.com.br/economia/noticia/2017-09/cai-producao-de-carvao-vegetal-lenha-e-madeira-em-tora-do-extrativismo> Acesso em: 11 de Julho de 2017.

BAIN, J. Industrial organization. New York: Wiley, 1959.

BIKKER, J. A.; HAAF, K. Competition and concentration review of the literature. Amsterdam: De Netherlands Bank, 2001.

BOFF, H.; RESENDE, M. Concentração Industrial. In: HASENCLEVER, L.; KUPFER, D. (Org.). Econo- 
mia industrial: fundamentos teóricos e práticas no Brasil. Rio de Janeiro: Campus, 2002. p. 73-90. CARVALHO, P. P. A convivência com o semiárido como estratégia para o combate à desertificação: uma experiência no Sertão do Araripe. Revista Agriculturas: Experiências em Agroecologia, Rio de Janeiro, v. 9, n. 3, dez. 2012. Disponível em: <http://aspta.org.br/wp-content/uploads/2013/04/Agriculturas-2013 SITE.pdf>. Acesso em: 14 abr. 2017.

CHAVES, A. G. C. Diagnóstico da exploração de lenha em planos de manejo sustentável na caatinga do Rio Grande do Norte. 2016. 47f. Dissertação (Mestrado em Ciências Florestais) - Universidade Federal do Rio Grande do Norte, Universidade Federal do Rio Grande do Norte, Natal, 2016.

CENTRO DE TECNOLOGIA DO GÁS E ENERGIAS RENOVÁVEIS - CTGAS. Diagnóstico da indústria de cerâmica vermelha do estado do Rio Grande do Norte. Relatório Final. Natal: CTGAS-ER; MCT; SEBRAE-RN, 2012. 134 p.

COELHO JUNIOR, L. M. Concentração regional do valor bruto de produção do pinhão no Paraná. Ciência Florestal, Santa Maria, v. 26, p. 853-861, out./dez. 2016.

COELHO JUNIOR, L. M.; REZENDE, J. L. P.; OLIVEIRA, A. D. Concentração das exportações mundiais de produtos florestais. Ciência Florestal, Santa Maria, v. 23, p. 693-703, out./dez. 2013.

COELHO JUNIOR, L. M.; SELVATTI, T. S.; ALENCAR, F. V.; SANTOS JUNIOR, E. P.; BORGES, L. A. C.; REZENDE, J. L. P. Global concentration of pulp exports. Floresta, v. 48, n. 4, p. 443-452, out/dez. 2018.

GINI, C. Variabilità e mutuabilità.Contributo allo studio delle distribuzioni e delle relazioni statistiche. Bologna: C. Cuppini, 1912.

HIRSCHMAN, A. O. National power and the structure of foreign trade. Berkley: University of California Press, 1945.

HIRSCHMAN, A. O. The Paternity of an Index. The American Economic Review, Pittsburgh, v. 54, n. 5, p. 761-762, sept. 1964.

HERFINDAHL, O. C., Concentration in the steel industry. Tese de doutoramento, Columbia University, 1950.

INSTITUTO BRASILEIRO DE GEOGRAFIA E ESTATÍSTICA - IBGE. Malhas digitais. Rio de Janeiro: IBGE, 2017b. Disponível em: <http://mapas.ibge.gov.br/pt/bases-e-referenciais/bases-cartograficas/ malhas-digitais>. Acesso em: 15 abr. 2017.

IBGE. Produção da extração vegetal e silvicultura 2015. Rio de Janeiro: IBGE, 2016. Disponível em: $<$ http://www.florestal.gov.br/snif/images/stories/ProducaoFlorestal/Extracao/analise_ibge_pevs\%202015. pdf $>$. Acesso em: 04 jul. 2017.

IBGE. SIDRA. Rio de Janeiro: IBGE, 2017a. Disponível em: <http://www.sidra.ibge.gov.br>. Acesso em: 02 fev. 2017.

IBÁ - Indústria Brasileira de Árvores. Relatório IBA 2015. São Paulo. 2014.

LIMA JUNIOR, C. Potencial do aproveitamento energético de fontes de biomassa na região nordeste do Brasil (Tese: Doutorado em Ciências, área de concentração: fontes renováveis) - Universidade Federal de Pernambuco. Recife, p. 91. 2013.

MACEDO, I. C. Estado da arte e tendências tecnológicas para energia. Brasília: Centro de Gestão e Estudos Estratégicos, 2003. 90 p.

MIRANDA, M. A. S. Potencial da biomassa florestal para produção de Energia térmica industrial. 2015. 61 f. Tese (Mestrado em Ciência Florestal) - Universidade Federal de Viçosa, Viçosa, MG, 2015.

POSSAS, M. L. Estruturas de mercado em oligopólio: economia e planejamento. 2. ed. São Paulo: Hucitec, 1999. $191 \mathrm{p}$.

REINALDO FILHO, L. L.; BEZERRA, F. D. Informe setorial cerâmica vermelha. Fortaleza: Banco do Nordeste, 2010. 22 p.

RESENDE, M. Medidas de concentração industrial: uma resenha. Análise Econômica, Rio de Janeiro, v. 11, p. 24-33, 1994.

SCHERER, F. M.; ROSS, D. Industrial market structure and economic performance. 3rd ed. Boston: Houghton Mifflin, 1990. 270 p.

SCHETTINI, B. L. S. et al. Avaliação da concentração do mercado mundial de pellets de madeira e as oportunidades para o Brasil. Enciclopédia Biosfera, [s. 1.], v. 13, p. 103-113, 2016. 
SIMIONI, F. J. et al. Evolução e concentração da produção de lenha e carvão vegetal da silvicultura no Brasil. Ciência Florestal, Santa Maria, v. 27, n. 2, p. 731-742, abr./jun. 2017.

SOARES, T. S. et al. Uso da biomassa florestal na geração de energia. Revista Científica Eletrônica de Engenharia Florestal, Garça, v. 4, n. 8, ago. 2006.

SOUZA, B. I; TRAVASSOS, I. S. Os negócios da lenha: indústria, desmatamento e desertificação no Cariri paraibano. GEOUSP - Espaço e Tempo (Online), São Paulo, v. 18, n. 2, p. 329-340, 2014.

THEIL, H. Economics and information theory. Amsterdam: North-Holland, 1967. 488 p. 